\title{
Do Inhaled Corticosteroids Alter Nasopharyngeal Flora in Children with Asthma?
}

\author{
KANA RAM JAT AND RAKESH LODHA \\ Department of Pediatrics, All India Institute of Medical Sciences, New Delhi, India. \\ rlodha1661@gmail.com
}

A

sthma is one of the most common chronic diseases in children. The inhaled corticosteroids (ICS) are the mainstay treatment for asthma, but ICS use may be associated with local adverse effects and possibly an increased risk of pneumonia. Asthma, itself, may be a risk factor for pneumonia. Though the exact mechanism is not well understood why asthma may increase the propensity for pneumonia, it is postulated that alteration in respiratory epithelial micro-environment by the inflammatory process of asthma and by immune modulation because of ICS may be some of the reasons [1]. Inflammation in asthma increases expression of platelet-activating factor receptor that promotes bacterial attachment resulting in more pneumococcal carriage [2]. The nasopharyngeal colonization of bacteria is the first step towards invasive infection by them, leading to pneumonia. A coinfection by a virus may result in pneumonia in children who already had nasopharyngeal colonization by bacteria [3]. Therefore, it is interesting to know the effects of ICS on carriage rate of pathogenic bacteria in nasopharyngeal flora in asthmatic children.

In the current issue of Indian Pediatrics, Nirmal, et al. [4] have reported an absence of association between use of ICS and isolation of pathogenic bacteria in the nasopharynx in a study on 75 children with asthma and 25 controls. Also, they found no effect of high doses of ICS on detection of pathogenic bacteria from nasopharynx. Among the risk factors for colonization with pathogenic bacteria, the authors reported that the use of biomass fuel for cooking at home increased the risk. The study is limited by a small sample size. It would have been interesting to assess the effects of ICS on the nasopharyngeal microbiome. One of the crucial questions will be whether vaccination with the pneumococcal vaccine will affect the carriage rate of $S$. pneumoniae and the development of pneumonia in children with asthma. In the index study, $25.3 \%$ of asthmatic children and $20 \%$ of controls received the pneumococcal vaccine, but the authors did not evaluate the effect of vaccination on carriage rate. Esposito, et al. [5] found the prevalence of $S$. pneumoniae carriage in $45.4 \%$ of 423 children and adolescents, but the carriage of $S$. pneumoniae was not different in children with asthma with or without receiving a 7-valent conjugate pneumococcal vaccine.

Previous studies have demonstrated a higher rate of nasopharyngeal colonization with $S$. pneumoniae in children with asthma compared to non-asthmatic children [6]. A study from Brazil reported that ICS were significantly associated with oropharyngeal colonization for $S$. pneumoniae in children [7]. In the same study, higher dose of ICS (19.4\% for dose of 100-300 $\mu \mathrm{g} v \mathrm{~s} 31.7 \%$ for dose of $400-800 \mu \mathrm{g} ; P=0.005)$ and prolonged duration of $\operatorname{ICS}(23.6 \%$ for duration $<6$ months vs $31.7 \%$ for duration $>6$ months; $P=0.0002)$ were risk factors for the colonization of $S$. pneumonia [7]. Though authors in the index study did not report the average duration of ICS use, there was a trend for increased colonization in children who received ICS for more than one year [4]. In a study among young adults, the oropharyngeal colonization by $S$. pneumoniae, group A streptococcus, Hemophilus influenzae, Moraxella catarrhalis and Neisseria meningitides was significantly more in asthmatics compared to non-asthmatics [8]. On other side, a study from China showed that throat flora were not different in children in control group and in children with asthma on ICS [9]. Alsuwaidi, et al. [10] also demonstrated no difference in nasopharyngeal isolation of bacteria and viruses in children with asthma and controls [10].

To sum up, the data are still inconsistent for the effect of asthma and ICS on nasopharyngeal carriage of pathogenic bacteria. The possible reasons for inconsistent results may be diverse geographical location of study sites, the number of children studied, and some unidentified factors. It is unclear whether a high dose of ICS is a risk factor for S. pneumoniae colonization or the severe asthma, for which high dose of ICS was used, is a risk factor for $S$. pneumoniae colonization.

Though index study did not follow the patients to see whether there is a difference in pneumonia in children with 
or without nasopharynx colonization [4], it will be prudent to know the effect of nasopharyngeal carriage of bacteria or virus for development of pneumonia in follow-up. Studies with larger sample size are needed to clarify the effect of asthma and ICS in different doses on nasopharyngeal/ oropharyngeal carriage rate of various pathogens. Future studies should also evaluate the impact of vaccination on the carriage rate and development of pneumonia in asthmatic children. The role of the nasopharyngeal microbiome in $S$. pneumoniae carriage and role of pneumococcal biofilms in the pneumococcal virulence in asthmatic children are other potential research areas.

Funding: None; Competing interests: None stated.

\section{REFERENCES}

1. Zaidi SR, Blakey JD. Why are people with asthma susceptible to pneumonia? A review of factors related to upper airway bacteria. Respirology. 2019;24:423-30.

2. van der Sluijs KF, van Elden LJR, Nijhuis M, Schuurman R, Florquin S, Shimizu T, et al. Involvement of the plateletactivating factor receptor in host defense against Streptococcus pneumoniae during postinfluenza pneumonia. Am J Physiol Lung Cell Mol Physiol. 2006;290:L194-9.

3. Wolter N, Tempia S, Cohen C, Madhi SA, Venter M, Moyes $\mathrm{J}$, et al. High nasopharyngeal pneumococcal density, increased by viral coinfection, is associated with invasive pneumococcal pneumonia. J Infect Dis. 2014;210:1649-57.

4. Nirmal G, Awasthi S, Gupta S, Aggarwal J. Effect of different doses of inhaled corticosteroids on the isolation of nasopharyngeal flora in children with asthma. Indian Pediatr. 2019;56:913-6.

5. Esposito S, Terranova L, Patria MF, Marseglia GL, Miraglia del Giudice M, Bodini A, et al. Streptococcus pneumoniae colonisation in children and adolescents with asthma: impact of the heptavalent pneumococcal conjugate vaccine and evaluation of potential effect of thirteen-valent pneumococcal conjugate vaccine. BMC Infect Dis. 2016;16:12.

6. Cardozo DM, Nascimento-Carvalho CM, Andrade A-LSS, Silvany-Neto AM, Daltro CHC, Brandão M-AS, et al. Prevalence and risk factors for nasopharyngeal carriage of Streptococcus pneumoniae among adolescents. J Med Microbiol. 2008;57:185-9.

7. Zhang L, Prietsch SOM, Mendes AP, Von Groll A, Rocha GP, Carrion L, et al. Inhaled corticosteroids increase the risk of oropharyngeal colonization by Streptococcus pneumoniae in children with asthma. Respirology. 2013;18:272-7.

8. Jounio U, Juvonen R, Bloigu A, Silvennoinen-Kassinen S, Kaijalainen $\mathrm{T}$, Kauma $\mathrm{H}$, et al. Pneumococcal carriage is more common in asthmatic than in non-asthmatic young men. Clin Respir J. 2010;4:222-9.

9. Lin H, Sun Y, Lin R, Xu J, Li N. [Influence of inhaled corticosteroids on distribution of throat flora in children with bronchial asthma]. Zhonghua Er Bi Yan Hou Tou Jing Wai Ke Za Zhi. 2010;45:656-9.

10. Alsuwaidi AR, Alkalbani AM, Alblooshi A, George J, Albadi G, Kamal SM, et al. Nasopharyngeal isolates and their clinical impact on young children with asthma: a pilot study. J Asthma Allergy. 2018;11:233-43. 